\title{
Effects of Naloxone and Diazepam on Blood Glucose Levels in Tramadol Overdose using Generalized Estimating Equation (GEE) Model; (An Experimental Study)
}

\section{Samaneh Nakhaee}

Birjand University of Medical Sciences

Khadijeh Farrokhfall

Birjand University of Medical Sciences

Ebrahim Miri-Moghaddam

Birjand University of Medical Sciences

Masoumeh Askari

Birjand University of Medical Sciences

Alireza Amirabadizadeh

Birjand University of Medical Sciences

Mohsen Foadoddini

Birjand University of Medical Sciences

Omid Mehrpour ( $\nabla$ omid.mehrpour@yahoo.com.au )

Birjand University of Medical Sciences

Research article

Keywords: Tramadol, diazepam, naloxone, blood glucose, overdose

Posted Date: February 12th, 2021

DOI: https://doi.org/10.21203/rs.3.rs-228531/v1

License: (c) (1) This work is licensed under a Creative Commons Attribution 4.0 International License. Read Full License 


\section{Abstract}

\section{Background:}

Tramadol poisoning is increasing around the world day by day. Tramadol is a synthetic opioid. Also, various treatments are applied for tramadol poisoning. Due to the unknown effects of tramadol poisoning and some of its treatments on blood glucose, this study was conducted to investigate the overdose of tramadol and its common treatments (naloxone, diazepam) and their combination on blood glucose in male rats.

\section{Methods:}

This study was conducted in 45 male Wistar rats. The animals were randomly divided into five groups of 9 rats. They received a $75 \mathrm{mg} / \mathrm{kg}$ dose of tramadol alone with naloxone, diazepam, and a combination of these two drugs. On the last day, animals' tail vein blood glucose levels (BGL) were measured using a glucometer at different times, including before the tramadol injection (baseline), one hour, three hours, and six hours after the tramadol injection. The rats were anesthetized and sacrificed 24 hours after the last injection. Blood samples were then taken, and the serum obtained was used to verify the fasting glucose concentration. Data were analyzed using SPSS software at a significance level of 0.05 using a one-way analysis of variance (ANOVA) and a generalized estimating equation (GEE).

\section{Results:}

According to the GEE model results, the diazepam and naloxone-diazepam groups showed blood glucose levels five units higher than the tramadol group $(p<0.05)$. The diazepam group had significantly higher blood glucose levels than the naloxone group $(p<0.05)$. The mean blood glucose levels before the intervention, three hours and six hours after the injection of tramadol did not differ between the groups, but the blood glucose levels one hour after the injection of tramadol in the group of naloxone were significantly lower than in the control group $(p<0.05)$. Blood glucose levels did not differ between the groups 24 hours after injection of tramadol.

\section{Conclusion:}

The results of the present study showed that tramadol overdose does not affect blood glucose levels. Diazepam alone and in combination with naloxone caused an increase in blood glucose levels in the tramadol overdose.

\section{Background:}

Tramadol is widely used throughout the world. This leads to an increase in the number of poisoning cases, side effects, and deaths [1]. Several cases of toxicity and abuse caused by this drug have been reported in the medical literature [2,3]. Tramadol is an effective pharmaceutical drug for moderate to severe pain relief that affects the transmission of pain impulses through the $\mu$-opioid receptor and 
inhibits norepinephrine reuptake serotonin [4]. The most important side effects of tramadol poisoning include gastrointestinal symptoms, drowsiness, seizures, respiratory distress, kidney failure, and rhabdomyolysis [5]. Tramadol overdose-induced blood glucose changes are another possible side effect that has received very little attention. These changes may be one of the predisposing factors for seizures in patients with tramadol overdose [6]. Altered blood glucose has been associated with changes in hepatic gluconeogenesis and peripheral glucose uptake [7].

In tramadol poisoning cases, several treatments are applied; however, there are some debates and challenges to the exact indications for using these treatments. The effects of these treatments have been investigated in tramadol-induced seizures [8-11], but their effects on blood glucose levels are less well studied. Naloxone can be used as an opioid antagonist to prevent respiratory depression in tramadol overdose cases [10]. Benzodiazepines, such as GABA inhibitors, are other drugs used in seizures caused by tramadol poisoning [12]. Several studies on these two drugs' effects on glucose metabolism have reported conflicting results [13-18]. To our knowledge, no studies have examined their effects on BGL when used to treat tramadol poisoning. This study was conducted to investigate tramadol, naloxone, diazepam, and their combination in male rats' blood glucose.

\section{Methods:}

This study was conducted in 45 male Wistar rats (bodyweight 200-250 g, 12 weeks) under standard laboratory conditions (constant room temperature $\left(22 \pm 2^{\circ} \mathrm{C}\right)$, light / dark periods of 12 hours, and free access to food and water). The rats were obtained from Research Centre of Experimental Medicine, Birjand University of Medical Sciences.

All animal experiments were approved by Institutional Animal Ethics Committee of Birjand University of medical sciences (Birjand, Iran) (code: IR.BUMS.REC.1397.194). This study was conducted in accordance with international and institutional guidelines for the care and use of animals. The ARRIVE (Animal Research: Reporting of in Vivo Experiments) guidelines for the standard care and use of animals were followed.

Naloxone, diazepam, and pentobarbital were obtained from Sigma-Aldrich and tramadol from Temad (Iran, Karaj). Diazepam and naloxone were dissolved in DMSO and tramadol in normal saline. The DMSO concentration in this study was $2 \%$. The injection volume was $1 \mathrm{ml}$ per $\mathrm{kg}$ of body weight. DMSO was prescribed in an inert range for behavioral [19] and experimental [20] animal studies.

Healthy animals with normal behavior and activity from same species, genders, weighing 200 to $250 \mathrm{gr}$ and ages of 12 weeks were included. Previously used rat in other experiments were not included.

Exclusion criteria were considered as death during experiment and animals with aberrant behavior. The animals were randomly divided into five groups, after one week of adaptation to laboratory conditions, including nine animals in each group: the control group, the tramadol group, the naloxone group, the diazepam group, and finally the naloxone-diazepam group. The calculation of sample size is based on 
the "resource equation approach" design for animal studies using the formula of $\mathrm{N}=(10 / k+1) \times k$, where $N$ $=$ total number of subjects, $k=$ number of groups [21].

- The control group (the first group) received intraperitoneally (IP) over 14 days, an injection of $0.9 \%$ normal saline.

- The tramadol group (the second group) received an intraperitoneal injection of $25 \mathrm{mg} / \mathrm{kg}$ of tramadol for 13 days. Subsequently, on day 14 , they received an intraperitoneal injection, $75 \mathrm{mg} / \mathrm{kg}$ of tramadol.

- The naloxone group (the third group) also received an intraperitoneal injection of $25 \mathrm{mg} / \mathrm{kg}$ of tramadol for 13 days. Subsequently, on day 14 , they were administered $75 \mathrm{mg} / \mathrm{kg}$ of tramadol by acute intraperitoneal injection, which was accompanied by naloxone $(2 \mathrm{mg} / \mathrm{kg})$ intravenously 15 minutes after the injection of tramadol. After all this, they received naloxone ( $4 \mathrm{mg} / \mathrm{kg})$ for up to 6 hours as an hourly injection [22].

- The diazepam group (the fourth group) for 13 days received $25 \mathrm{mg} / \mathrm{kg}$ of tramadol intraperitoneally. Subsequently, on day 14 , they were administered tramadol, also intraperitoneally, $75 \mathrm{mg} / \mathrm{kg}$ of acute dose. Then, 15 minutes after the tramadol injection, they were administered $1.77 \mathrm{mg} / \mathrm{kg}$ of diazepam intraperitoneally.

- The naloxone-diazepam group (fifth group) received $25 \mathrm{mg} / \mathrm{kg}$ of tramadol intraperitoneally over a period of 13 days. On day 14, they were injected intraperitoneally with tramadol at an acute dose of $75 \mathrm{mg} / \mathrm{kg}$, an injection of $1.77 \mathrm{mg} / \mathrm{kg}$ of intraperitoneal diazepam, and intravenous naloxone at a dose of $2 \mathrm{mg} / \mathrm{kg}$. Finally, for up to 6 hours, they received an injection of $4 \mathrm{mg} / \mathrm{kg}$ of naloxone every hour.

On the last day, the rat tail vein blood glucose levels were measured using a glucometer by making a $2 \mathrm{~mm}$ transverse incision at the end of the animal's tail. On the fourteenth day, blood glucose was measured in all groups at different times, even before injection of Tramadol (baseline), one hour, three hours, and six hours after tramadol injection. Rats were anesthetized and sacrificed by intraperitoneal administration of $60 \mathrm{mg} / \mathrm{kg}$ of pentobarbital 24 hours after the last injection (fasting for 12 to 14 hours). Blood samples were then taken. Serum was obtained by centrifugation of the samples and stored at $-80^{\circ}$ $\mathrm{C}$ until the glucose level was measured. The serum achieved was used to evaluate the fasting glucose concentration. The experimenter was aware of the rat group, but a researcher blinded to the group allocation carried out statistical analysis and outcome assessment.

After collection, the data were entered into the SPSS software (version. 16). Using the Shapiro Wilk test, the hypothesis of normality of the quantitative variables was examined. One-way analysis of variance (ANOVA) and Bonferroni's post hoc test was used to compare means in various groups. The generalized estimation equation (GEE) model was also used to analyze the longitudinal variables of blood glucose at different times. The longitudinal variable was entered as a dependent variable in the GEE model and the group as an explanatory variable. The level of significance was considered less than 0.05 . 


\section{Results:}

One death occurred in the naloxone-diazepam group during the study. Before and after the study, the mean weight of the rats did not differ between the groups $(p>0.05)$. The ANOVA test results showed that the mean blood glucose levels before the intervention, three hours and six hours after the injection of tramadol did not differ between the groups, but one hour after the injection of tramadol in the naloxone group was significantly lower than in the control group. There was no significant difference between the other groups (Fig. 1).

According to this study results, the mean blood glucose levels 24 hours after tramadol injection did not differ between the groups (Fig. 2).

The diazepam and naloxone-diazepam groups showed blood glucose levels five units higher than the tramadol group based on the GEE model results $(p<0.05)$. Furthermore, the diazepam group had significantly higher blood glucose levels than the naloxone group $(p<0.05)$. The other groups did not show significant effects on blood glucose compared to each other $(p>0.05)$ (Table 1$)$.

Table 1

Comparison of glucose levels in the different groups based on the GEE model

\begin{tabular}{|lllll|}
\hline Variable & B & SE & Wald & p-value \\
\hline Tramadol vs Control & -10.25 & 5.24 & 3.81 & 0.05 \\
\hline Naloxone vs Control & -11.86 & 6.45 & 3.38 & 0.07 \\
\hline Diazepam vs Control & -4.82 & 4.60 & 1.09 & 0.29 \\
\hline Naloxone-Diazepam vs Control & -5.15 & 3.37 & 2.33 & 0.13 \\
\hline Naloxone vs Tramadol & -1.61 & 3.23 & 0.25 & 0.62 \\
\hline Diazepam vs Tramadol & 5.43 & 2.10 & 6.68 & 0.01 \\
\hline Naloxone-Diazepam vs Tramadol & 5.09 & 2.09 & 5.91 & 0.01 \\
\hline Diazepam vs Naloxone & 7.04 & 2.47 & 8.10 & 0.004 \\
\hline Naloxone-Diazepam vs Naloxone & 6.71 & 3.89 & 2.97 & 0.08 \\
\hline Naloxone-Diazepam vs Diazepam & -0.36 & 2.40 & 0.02 & 0.88 \\
\hline
\end{tabular}

All study groups, except the control group, showed a similar pattern in blood glucose changes at different times, such that one hour after tramadol injection, they all showed a decrease in blood glucose levels, and these values returned nearly close to baseline levels three hours after injection (Fig. 3).

\section{Discussion:}


The results of this study showed that tramadol overdose does not affect blood glucose levels, although its changes are aimed at lowering blood glucose. Conflicting results have been reported in several studies. Some studies have reported hypoglycemia in tramadol poisoning [5, 6, 23-32], and others have reported elevated blood glucose levels in these individuals [6, 24, 33, 34]. Consistent with our results, several studies have shown normal blood glucose levels in people with tramadol poisoning $[4,6,23-25$, $35,36]$.

The different results in different studies can be attributed to differences in the samples studied, different doses of tramadol, different measurement times of BGL, and various forms of administration. The proposed mechanism for tramadol's hypoglycemic effects is the activation of opioid receptors by tramadol, resulting in glucose utilization in peripheral tissues [37].

Previous reports indicate that the opioid receptor is the main target involved in the hypoglycemic mechanism[38]..

Some studies also showed that serotonin could increase insulin levels, release beta-endorphins, and ultimately stimulate muscle glucose utilization $[39,40]$.

Catecholamines have been shown to directly suppress insulin secretion from the pancreas, causing glycogenolysis in the liver by stimulating the a-adrenergic receptor and ultimately causing hyperglycemia $[41,42] .$. Some studies showed a hyperglycemic effect of tramadol. For example, Kara et al. (2013) attributed the induction of tramadol-induced hyperglycemia to a2 adrenergic receptors' activity, suggesting that monoamine pathways effectively affect the analgesic effects of tramadol and may be involved in the development of drug-induced hyperglycemia [43]. Another result of this study was the increasing effect of diazepam alone and in combination with naloxone on BGL. Diazepam is widely used as a sedative and an anticonvulsant. The benzodiazepine receptor mediates its action by increasing synaptic GABA inhibition [44]and, according to some reports, prevents various stress-induced changes, such as activation of the HPA axis [45]. Dexit et al. prescribed diazepam $(0.6 \mathrm{mg} / \mathrm{kg} / \mathrm{day})$ to rabbits for one month and reported no effect on blood glucose [46].

In contrast, some studies have reported that diazepam increases blood glucose in humans and animals. For example, the results of a study in mice showed that administration of diazepam $(13.3 \mathrm{mg} / \mathrm{kg})$ resulted in an increase in blood glucose at different times after injection [18]. Another study in rabbits showed that diazepam ( $2 \mathrm{mg} / \mathrm{kg} / \mathrm{iv}$ ) could increase blood glucose levels [47].

Furthermore, another study in rats showed that diazepam could increase blood glucose levels in a dosedependent manner [48]. Their research suggested that diazepam effects on peripheral glucose were the possible cause of benzodiazepine-related hyperglycemia [48]. In an experimental model, the 2a-

adrenergic receptor antagonist was able to prevent diazepam-induced hyperglycemia. The results of this study suggested that diazepam-induced hyperglycemia may be associated with adrenaline release from the adrenal gland [44]. 
The GABA-A receptor subunit expression has also been reported in the pancreas [49] and chromaffin cells of the adrenal medulla [50]. GABA can regulate the endocrine function of $\beta$ cells through direct or indirect activation [51].

It is hard to explain the glycemic changes of diazepam at an animal stage of examination, and the results should be interpreted with caution at the animal stage.

The effects of diazepam also need to be interpreted in the context of tramadol poisoning due to drug interactions. The racial and dose-dependent characteristics of glucose homeostasis must be considered when interpreting the results of various studies. And we propose to investigate these treatments in several doses. Different single-dose therapies were used in tramadol overdose in this study.

Additionally, future studies may consider providing a dose-response curve and other factors related to blood glucose homeostasis.

The generalization of animals' findings to humans should be made with caution due to this study's empirical nature. Assume that these treatments' effects on blood glucose and glucose homeostasis in human tramadol overdose, the hyperglycemic effects of diazepam, and the hypoglycemic effects of naloxone in the early hours must be considered especially for people with diabetes.

\section{Conclusion:}

The results of our study cleared that tramadol overdose had minimal effects on blood glucose levels. Naloxone can also lower blood glucose levels in the first hours after tramadol injection, and Diazepam alone and in combination with naloxone may increase blood glucose levels in the event of a tramadol overdose.

\section{Abbreviations}

GEE: generalized estimating equation, GABA: $\gamma$-Aminobutyric acid, DMSO: Dimethyl sulfoxide, IP: intraperitoneal, BGL: blood glucose levels, ANOVA: one-way analysis of variance

\section{Declarations}

\section{Ethics approval and consent to participate}

All animal experiments were approved by Institutional Animal Ethics Committee of Birjand University of medical sciences (Birjand, Iran) (code: IR.BUMS.REC.1397.194). This study was conducted in accordance with international and institutional guidelines for the care and use of animals. The ARRIVE (Animal Research: Reporting of in Vivo Experiments) guidelines for the standard care and use of animals were followed. 


\section{Consent for publication}

Not applicable

\section{Availability of data and materials}

The datasets are available from the corresponding author on formal and logic request

\section{Competing Interests}

The authors take full responsibility for the writing and content of this article and confirm that there are no conflicts of interests associated with this academic publication

\section{Funding}

This study was supported by grants from the research council of Birjand University of Medical Sciences (Grant number: 455668), Birjand, Iran, and from the Iran National Science Foundation (INSF) (Grant number: 97012231). The funding body had no role in the design of the study and collection, analysis, and interpretation of data and in writing the manuscript.

\section{Authors' contributions}

$\mathrm{SN}, \mathrm{KF}, \mathrm{EM}, \mathrm{MF}, \mathrm{OM}$ contributed to conception, design, and preparation of the manuscript. SN, KF, MA, AA, $\mathrm{OM}$ contributed to conducting experiments, acquisition, analysis, and interpretation. SN, KF, EM, MF, MA, $\mathrm{AA}$, and $\mathrm{OM}$ made substantial contributions in drafting the manuscript and revising it critically for important intellectual content. All authors have read and approved the final version of manuscript.

\section{Acknowledgements}

Not applicable

\section{References}

1. Nakhaee S, Brent J, Hoyte C, Farrokhfall K, Shirazi FM, Askari M, Mehrpour O. The effect of tramadol on blood glucose concentrations: a systematic review. Expert Review of Clinical Pharmacology 2020:1-13.

2. Doostmohammadi $M$, Rahimi H-R. ADME and toxicity considerations for tramadol: from basic research to clinical implications. Expert Opinion on Drug Metabolism \& Toxicology 2020. 
3. Nakhaee S, Amirabadizadeh A, Brent J, Miri-Moghaddam E, Foadoddini M, Farrokhfall K, Hosseini M, Abdollahi M, Mehrpour O: Tramadol and the occurrence of seizures: a systematic review and metaanalysis. Critical reviews in toxicology 2019, 49(8):710-723.

4. Ghazimirsaeid SA, Khakzad M, Dinpanah H, Amani N, Rahimi M, Manuchehri AA. Tramadol, seizure caused by an overdose and acute renal failure: a case report. World Applied Sciences Journal. 2014;32(7):1204-8.

5. Majidi M, Nekouei Fard S. Refractory seizures in tramadol poisoning: a case report. Iranian Journal of Toxicology. 2014;8(26):1157-9.

6. Nasouhi S, Talaie H, Pajoumand A, Aghapour S, Rahimi M, Khorasani AG, Mashayekhian M, Aghabiklooei A, Razi P, Mahdavinejad A. Hypo and hyperglycemia among tramadol overdose patients in Loghman Hakim Hospital, Tehran, Iran. Pak J Pharm Sci. 2015;28(6):1959-63.

7. Nelson LS, Juurlink DN. Tramadol and hypoglycemia: one more thing to worry about. JAMA internal medicine. 2015;175(2):194-5.

8. Shadnia S, Brent J, Mousavi-Fatemi K, Hafezi P, Soltaninejad K. Recurrent seizures in tramadol intoxication: implications for therapy based on 100 patients. Basic Clin Pharmacol Toxicol. 2012;111(2):133-6.

9. Farzaneh E, Mostafazadeh B, Mehrpour O. Seizurogenic effects of low-dose naloxone in tramadol overdose. Iranian Journal of Pharmacology Therapeutics. 2012;11(1):6-0.

10. Eizadi-Mood N, Ozcan D, Sabzghabaee AM, Mirmoghtadaee P, Hedaiaty M. Does naloxone prevent seizure in tramadol intoxicated patients? International journal of preventive medicine. 2014;5(3):302.

11. Saidi H, Ghadiri M, Abbasi S, Ahmadi S-F. Efficacy and safety of naloxone in the management of postseizure complaints of tramadol intoxicated patients: a self-controlled study. Emerg Med J. 2010;27(12):928-30.

12. Lagard C, Chevillard L, Malissin I, Risède P, Callebert J, Labat L, Launay J-M, Laplanche J-L, Mégarbane B. Mechanisms of tramadol-related neurotoxicity in the rat: Does diazepam/tramadol combination play a worsening role in overdose? Toxicol Appl Pharmacol. 2016;310:108-19.

13. Theodore WH, Leiderman D, Gaillard W, Khan I, Reeves P, Lloyd-Hontz K. The effect of naloxone on cerebral blood flow and glucose metabolism in patients with complex partial seizures. Epilepsy research. 1993;16(1):51-4.

14. Morley JE, Baranetsky NG, Wingert TD, Carlson HE, Hershman JM, Melmed S, Levin SR, Jamison KR, Weitzman R, CHANG RJ. Endocrine effects of naloxone-induced opiate receptor blockade. The Journal of Clinical Endocrinology Metabolism. 1980;50(2):251-7.

15. Ipp E, Garberoglio C, Richter H, Moossa AR, Rubenstein AH. Naloxone decreases centrally induced hyperglycemia in dogs: evidence for an opioid role in glucose homeostasis. Diabetes. 1984;33(7):619-21.

16. Syvälahti E, Kanto J. Serum growth hormone, serum immunoreactive insulin and blood glucose response to oral and intravenous diazepam in man. International Journal of Clinical Pharmacology Biopharmacy. 1975;12(1-2):74-82. 
17. Schaira VRL, Ranali J, Saad MJA, De Oliveira PC, Ambrosano GMB, Volpato MC. Influence of diazepam on blood glucose levels in nondiabetic and non-insulin-dependent diabetic subjects under dental treatment with local anesthesia. Anesth Prog. 2004;51(1):14.

18. Mohammed A, Al-Hozab A, Alshaheen T. Effects of diazepam and xylazine on changes of blood oxygen and glucose levels in mice. Adv Anim Vet Sci. 2018;6(3):121-7.

19. Cavas M, Beltrán D, Navarro JF. Behavioural effects of dimethyl sulfoxide (DMSO): changes in sleep architecture in rats. Toxicology letters. 2005;157(3):221-32.

20. Malfará WR, Souza AMd, Queiroz RHC. Ranitidine treatment inducing methemoglobinemia in male Wistar rats. Revista Brasileira de Ciências Farmacêuticas. 2005;41(2):247-52.

21. Arifin WN, Zahiruddin WM. Sample size calculation in animal studies using resource equation approach. The Malaysian journal of medical sciences: MJMS. 2017;24(5):101.

22. Lagard $C$, Malissin I, Indja W, Risède $P$, Chevillard L, Mégarbane $B$. Is naloxone the best antidote to reverse tramadol-induced neuro-respiratory toxicity in overdose? An experimental investigation in the rat. Clinical Toxicology 2017:1-7.

23. Moulis F, Rousseau V, Abadie D, Masmoudi K, Micallef J, Vigier C, Pierre S, Dautriche A, Montastruc F, Montastruc J-L. Serious adverse drug reactions with tramadol reported to the French pharmacovigilance database between 2011 and 2015. Therapie. 2017;72(6):615-24.

24. Fouad S, Hassan N, Nassief N, El-Halawany F, Hussien R. Critical score as a predictor for progression of tramadol intoxication. J Clin Toxicol. 2015;5(249):2161-0495.1000249.

25. Othong R, Srisang W. Tramadol-induced seizures in adolescents and young adults in Bangkok: Clinical features and emergency management. J Med Assoc Thai. 2018;101(8):167-75.

26. Mugunthan N, Davoren P. Danger of hypoglycemia due to acute tramadol poisoning. Endocr Pract. 2012;18(6):e151-2.

27. Granauro P, Di Comite V, Lippi G, Marzi U, Cervellin G. Severe acute lactic acidosis and hypoglycemia due to isolate tramadol poisoning. Emergency Care Journal. 2016;12(2):40-1.

28. Aliyu I, Kyari F, Ibrahim Z. Hypoglycemia in a Child with Tramadol Poisoning. Saudi J Med Med Sci. 2016;4(1):35-7.

29. Ly BT, Thornton SL, Buono C, Stone JA, Wu AH. False-positive urine phencyclidine immunoassay screen result caused by interference by tramadol and its metabolites. Ann Emerg Med. 2012;59(6):545-7.

30. Elkalioubie A, Allorge D, Robriquet L, Wiart J-F, Garat A, Broly F, Fourrier F. Near-fatal tramadol cardiotoxicity in a CYP2D6 ultrarapid metabolizer. Eur J Clin Pharmacol. 2011;67(8):855-8.

31. El-Hussuna A, Arnesen RB, Rosenberg J. Tramadol poisoning with hyperamylasemia. BMJ case reports. 2010;2010:bcr0320102821.

32. De Decker K, Cordonnier J, Jacobs W, Coucke V, Schepens P, Jorens PG: Fatal intoxication due to tramadol alone: case report and review of the literature. Forensic science international 2008 , 175(1):79-82. 
33. Wang S-Q, Li C-S, Song Y-G. Multiply organ dysfunction syndrome due to tramadol intoxication alone. Am J Emerg Med. 2009;27(7):903. e905-903. e907.

34. Elyazji NR, Abdel-Aziz I, Aldalou A, Shahwan O. The effects of tramadol hydrochloride administration on the hematological and biochemical profiles of domestic male rabbits. IUG Journal of Natural studies 2015, 21(2).

35. Nasr MA, Mahmoud SF, Mohammed MA, El-samie HSA. A Study of Clinical and Laboratory Picture of Acute Tramadol Toxicity in Damietta Governorate.

36. TRAMADOL®... Beyond its beneficial effects. J Clin Toxicol 2016, 6(1):282.

37. Cheng JT, Liu IM, Chi TC, Tzeng TF, Lu FH, Chang CJ. Plasma glucose-lowering effect of tramadol in streptozotocin-induced diabetic rats. Diabetes. 2001;50(12):2815-21.

38. Grandvuillemin A, Jolimoy G, Authier F, Dautriche A, Duhoux F, Sgro C. Tramadol-induced hypoglycemia. Presse Med. 2006;35(12):1842-4.

39. Yamada J, Sugimoto Y, Kimura I, Takeuchi N, Horisaka K. Serotonin-induced hypoglycemia and increased serum insulin levels in mice. Life sciences. 1989;45(20):1931-6.

40. Chi T-C, Ho Y-J, Chen W-P, Chi T-L, Lee S-S, Cheng J-T, Su M-J. Serotonin enhances $\beta$-endorphin secretion to lower plasma glucose in streptozotocin-induced diabetic rats. Life sciences. 2007;80(20):1832-8.

41. Porte $D$. A receptor mechanism for the inhibition of insulin release by epinephrine in man. $J$ Clin Investig. 1967;46(1):86-94.

42. Bole D, Simon B. Pheochromocytoma-induced hyperglycemia leading to misdiagnosis of type 1 diabetes mellitus. AACE Clinical Case Reports. 2017;3(1):e83-6.

43. Kara H, Karci A, Gümüştekin $M$, Örmen $M$, Taşdöğen A, Elar Z. The Effect of Tramadol on Blood Glucose Levels in Rats. Open Journal of Anesthesiology. 2013;3(01):18.

44. Yamada J, Sugimoto Y, Noma T. Involvement of adrenaline in diazepam-induced hyperglycemia in mice. Life sciences. 2000;66(13):1213-21.

45. Sugimoto Y, Yamada J, Noma T. Effects of anxiolytics, diazepam and tandospirone, on immobilization stress-induced hyperglycemia in mice. Life sciences. 1998;63(14):1221-6.

46. Dixit R, Puri J, Sharma M, Jain I, Singh S, Ansari N, Singh S: Effect of anxiolytics on blood sugar level in rabbits. 2001.

47. Sarov M, Ilieva G. Diazepam impairs glucose tolerance and increases serum glucose in NZW rabbits. Comptes Rendus de l'Academie Bulgare des Sciences. 2003;56(11):11: 77.

48. Salice V, Valenza F, Pizzocri M, Valenti L, Chevallard G, Umbrello M, Gatti S, Fargion S, lapichno G, Gattinoni L. Benzodiazepines induce hyperglycemia in rats by affecting peripheral disposal of glucose. Crit Care. 2013;17(2):1-200.

49. Borboni P, Porzio O, Fusco A, Sesti G, Lauro R, Marlier L. Molecular and cellular characterization of the GABAA receptor in the rat pancreas. Molecular cellular endocrinology. 1994;103(1-2):157-63. 
50. Parramón M, Oset-Gasque M, Gonzalez M, Stephenson F. Identification of GABAA receptor subunits expressed in bovine adrenal medulla. Neurosci Lett. 1994;168(1-2):243-6.

51. Brice N, Varadi A, Ashcroft S, Molnar E. Metabotropic glutamate and GABAB receptors contribute to the modulation of glucose-stimulated insulin secretion in pancreatic beta cells. Diabetologia. 2002;45(2):242-52.

\section{Figures}

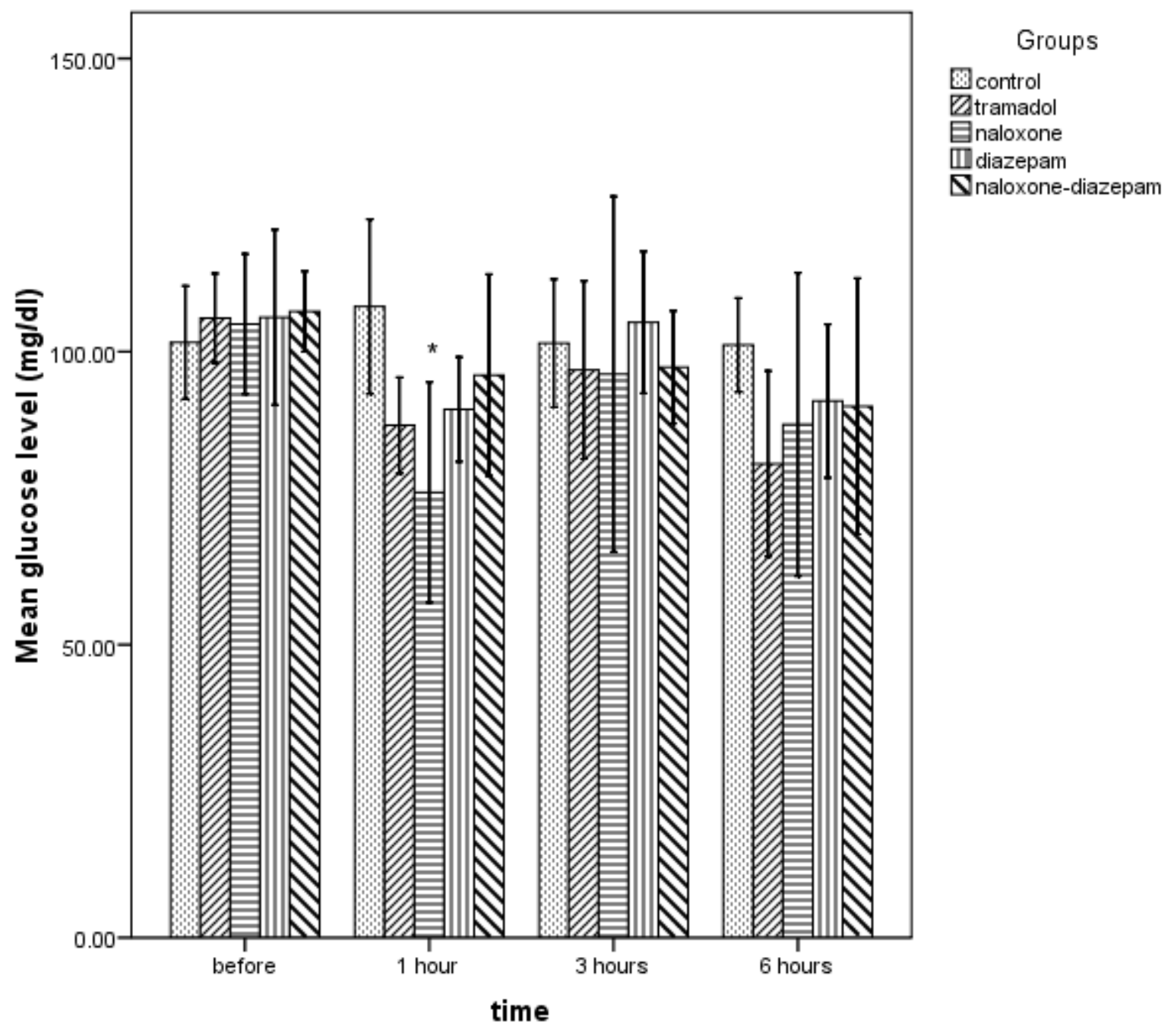

Figure 1

Comparison of blood glucose levels in different times clustered by groups. Data are the mean \pm SD. ${ }^{*} p<$ 0.05 comparison between groups. 


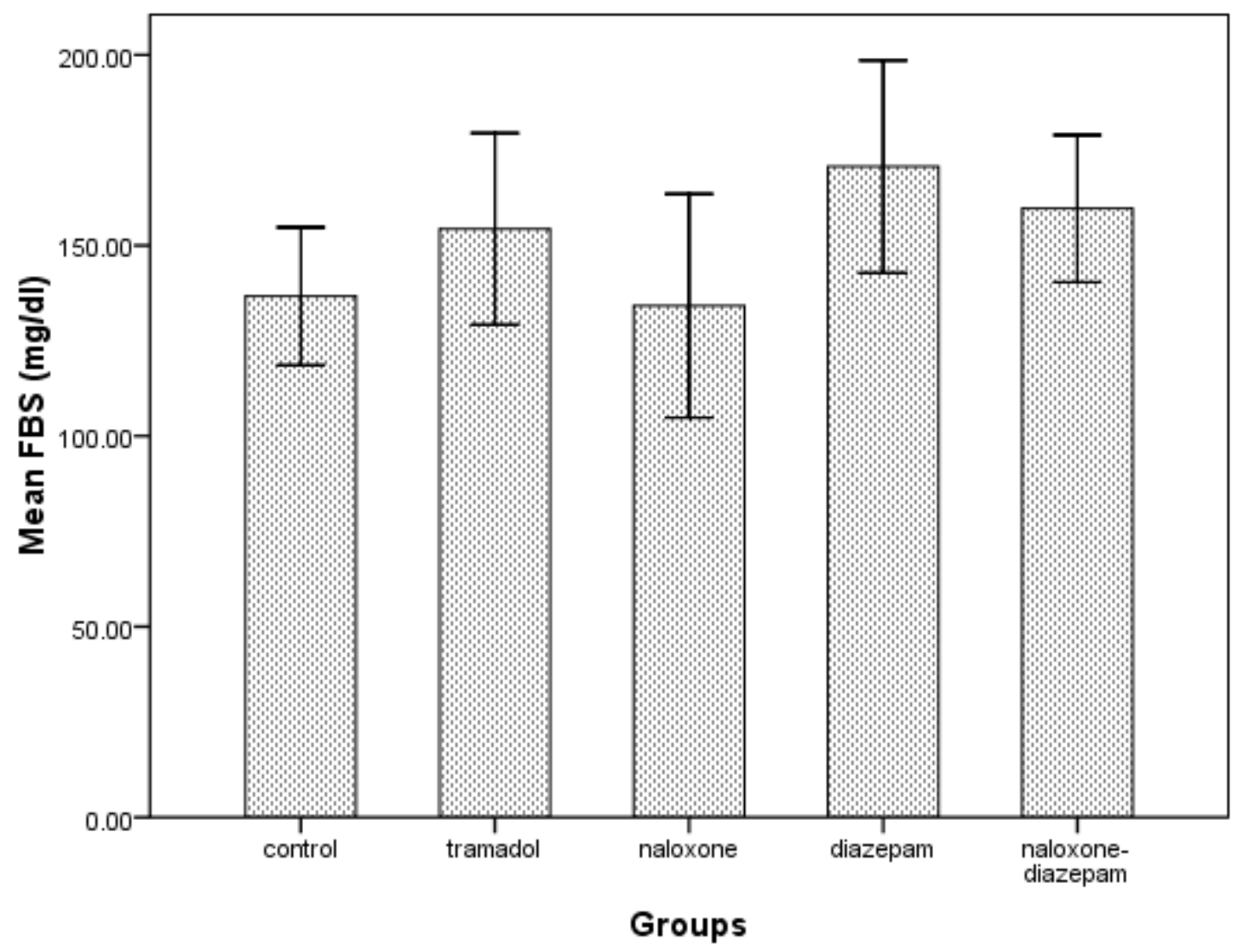

Figure 2

Comparison of fasting blood glucose levels in different groups after 24 hours. Data are the mean \pm SD. 


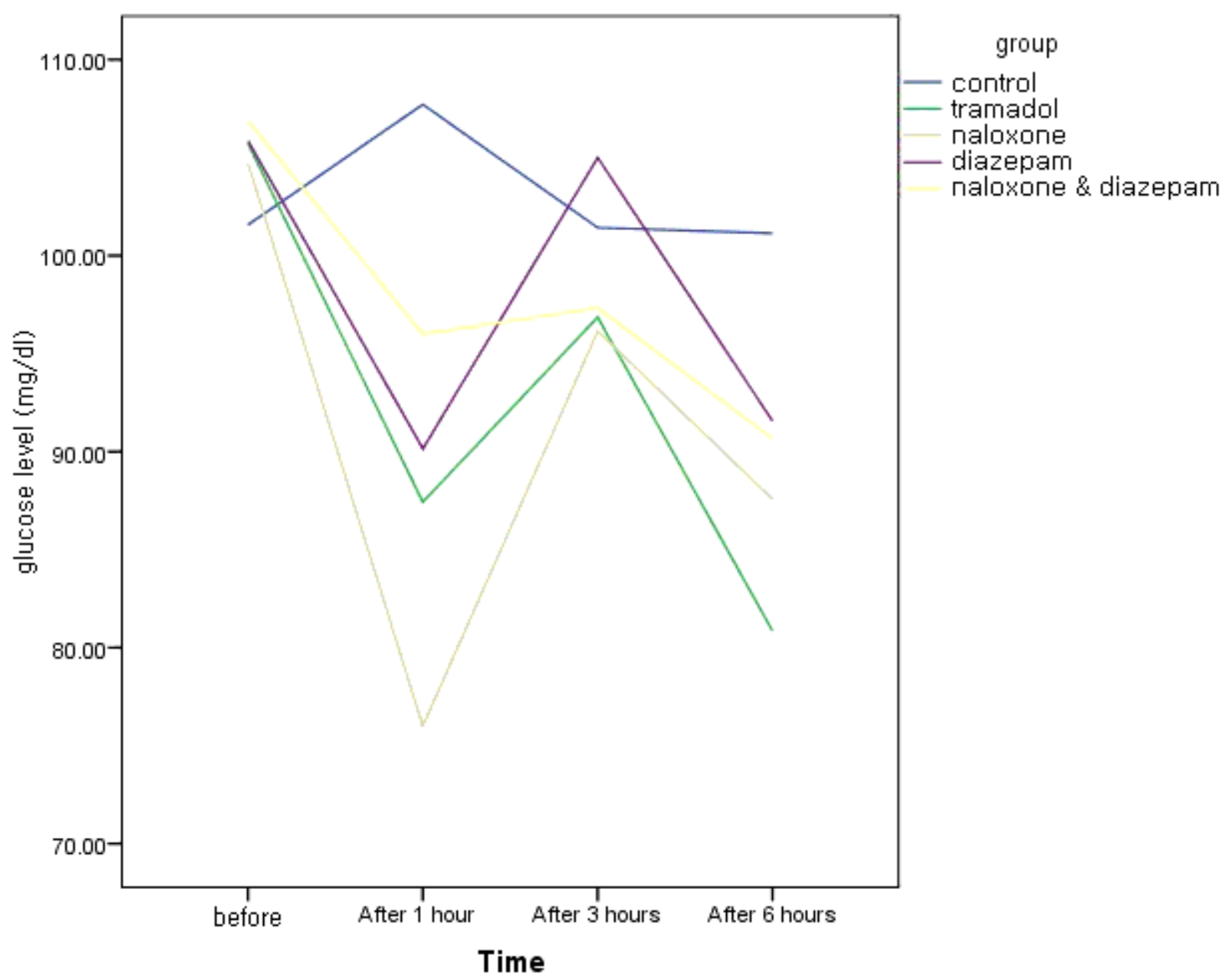

Figure 3

Time-course of average glucose levels in the different treatment groups

\section{Supplementary Files}

This is a list of supplementary files associated with this preprint. Click to download.

- AuthorChecklistE10only.pdf 